\title{
Manejo de falha óssea em fratura da região distal do fêmur pela técnica de Masquelet com enxerto de fíbula associado a enxerto de crista ilíaca: Relato de dois casos*
}

\section{Management of Bone Failure in Fracture of the Distal Region of the Femur Using the Masquelet Technique with Fibula Graft Associated with Iliac-Crest Graft: Report of Two Cases}

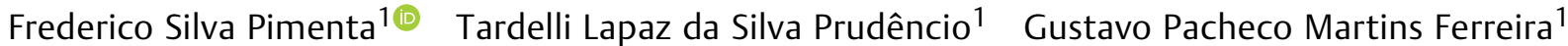 \\ Alessandro Cordoval de Barros ${ }^{1}$ Marco Túlio Lopes Caldas ${ }^{1}$ Heitor Maia Rodrigues ${ }^{1}$ \\ ${ }^{1}$ Serviço de Ortopedia e Traumatologia, Hospital Maria Amélia Lins, \\ Belo Horizonte, Minas Gerais, Brasil \\ Endereço para correspondência Frederico Silva Pimenta, MsC, Rua do \\ Campo 130, apt. 802, Vila da Serra, Nova Lima, Minas Gerais, \\ 34006-062, Brasil (e-mail: fredericopimenta86@hotmail.com).
}

Rev Bras Ortop 2022;57(6):1074-1078.

\section{Resumo \\ Palavras-chave \\ - enxerto ósseo \\ - pseudoartrose \\ - fraturas do fêmur}

Dois casos de falha óssea após fratura da região distal do fêmur tratados pela técnica de Masquelet são apresentados. O primeiro caso envolve uma perda óssea aguda, e o segundo, uma pseudoartrose. $\mathrm{O}$ manejo adequado dessas lesões levou à consolidação e a um bom resultado funcional.

Two cases of bone failure after fracture of the distal region of the femur treated with the Masquelet technique are presented. The first case involves acute bone loss, and the second, pseudarthrosis. The proper management of these lesions led to consolidation and a good functional result.

- bone graft

- pseudarthrosis

- femur fractures

\section{Introdução}

O tratamento de grandes perdas ósseas após fratura de ossos longos é desafiador para o ortopedista. O transporte ósseo com o uso do método de Ilizarov está associado com complicações e grande morbidade. ${ }^{1}$ Uma opção de tratamento é a

Trabalho desenvolvido no Serviço de Ortopedia e Traumatologia, Hospital Maria Amélia Lins, Belo Horizonte, Minas Gerais, Brasil. técnica de Masquelet, na qual é formada uma membrana ricamente vascularizada. $\mathrm{O}$ procedimento ocorre em dois estágios: no primeiro, um espaçador de cimento ósseo é utilizado para preencher o defeito, e, no segundo estágio, o espaçador é removido e o defeito é preenchido com enxerto ósseo. ${ }^{2-5}$

Dois casos de grande falha óssea do fêmur distal são relatados. O primeiro caso envolveu uma perda óssea aguda, ocorrida após fratura exposta do fêmur. No segundo caso, o paciente foi

(C) 2020. Sociedade Brasileira de Ortopedia e Traumatologia. All rights reserved.

This is an open access article published by Thieme under the terms of the Creative Commons Attribution-NonDerivative-NonCommercial-License, permitting copying and reproduction so long as the original work is given appropriate credit. Contents may not be used for commercial purposes, or adapted, remixed, transformed or built upon. (https://creativecommons.org/ licenses/by-nc-nd/4.0/)

Thieme Revinter Publicações Ltda., Rua do Matoso 170, Rio de Janeiro, RJ, CEP 20270-135, Brazil 

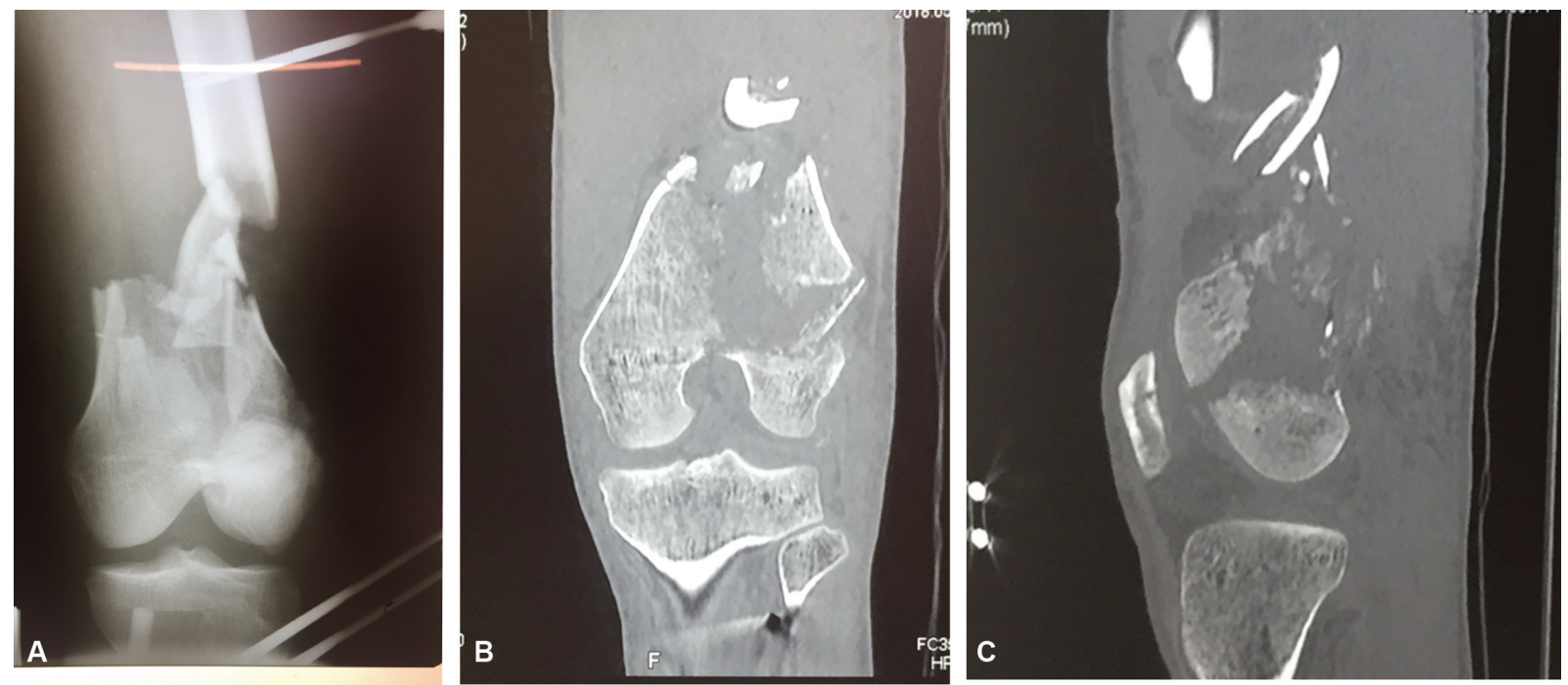

Fig. 1 (A) Radiografia em incidência anteroposterior (AP) do joelho demonstrando falha óssea. (B) Tomografia computadorizada (TC) em corte coronal demonstrando perda óssea e pequeno fragmento articular do côndilo femoral lateral, e (C) em corte sagital de fratura de Hoffa associada.

tratado inicialmente de forma aguda devido à fratura distal do fêmur, e evoluiu com pseudoartrose dessa região.

\section{Relato de Caso}

\section{Caso 1}

Paciente do sexo masculino, 24 anos, vítima de colisão entre motocicleta e automóvel, apresentou fratura exposta da região distal do fêmur $\mathrm{AO}$ 33C3, de grau 3B segundo a classificação de Gustilo et $\mathrm{al}^{6}$, e perda óssea (-Fig. 1). A abordagem inicial envolveu extenso desbridamento e fixação externa transarticular do joelho. Sete dias após o trauma, procedeu-se à fixação da fratura com uma placa bloqueada medial por meio de um acesso anterior e artrotomiaparapatelar medial, e novo desbridamento com coleta de material para cultura. 0 defeito ósseo de $9 \mathrm{~cm}$ foi preenchido com $40 \mathrm{~g}$ de cimento ortopédico com $2 \mathrm{~g}$ de vancomicina (-Fig. 2 A e B).

As culturas foram negativas e, após seis semanas, o paciente foi submetido ao segundo tempo cirúrgico. O cimento foi removido, e a falha óssea, preenchida com enxerto de fíbula não vascularizada ipsilateral e enxerto ósseo de crista ilíaca. Uma nova placa lateral foi acrescentada para maior rigidez da construção ( - Fig. 2C e D). O apoio com carga parcial foi iniciado com quatro meses, e, após um ano, a fratura se consolidou. A amplitude de movimento do joelho foi de $0^{\circ}$ a $130^{\circ}$, e a discrepância dos membros, menor do que $1,0 \mathrm{~cm}$ (-Fig. $\mathbf{3}$ ).

\section{Caso 2}

Paciente do sexo masculino, 22 anos, vítima de uma colisão de moto contra umposte de luz, apresentou fratura exposta da região distal do fêmur $\mathrm{AO} 33 \mathrm{C}$, de grau 3B segundo a classificação de Gustilo et $\mathrm{al}^{6}$, com perda óssea de $4 \mathrm{~cm}$. A abordagem inicial envolveu desbridamento e fixador externo transarticular. Após dez dias, procedeu-se à fixação definitiva, e o defeito foi preenchidocom enxerto de crista ilíaca. O paciente evoluiu com infecção aguda da osteossíntese, e foram feitosdois desbridamentos e administrada antibioticoterapia venosa. A infecção foi controlada e, após um ano do procedimento, a placa foi
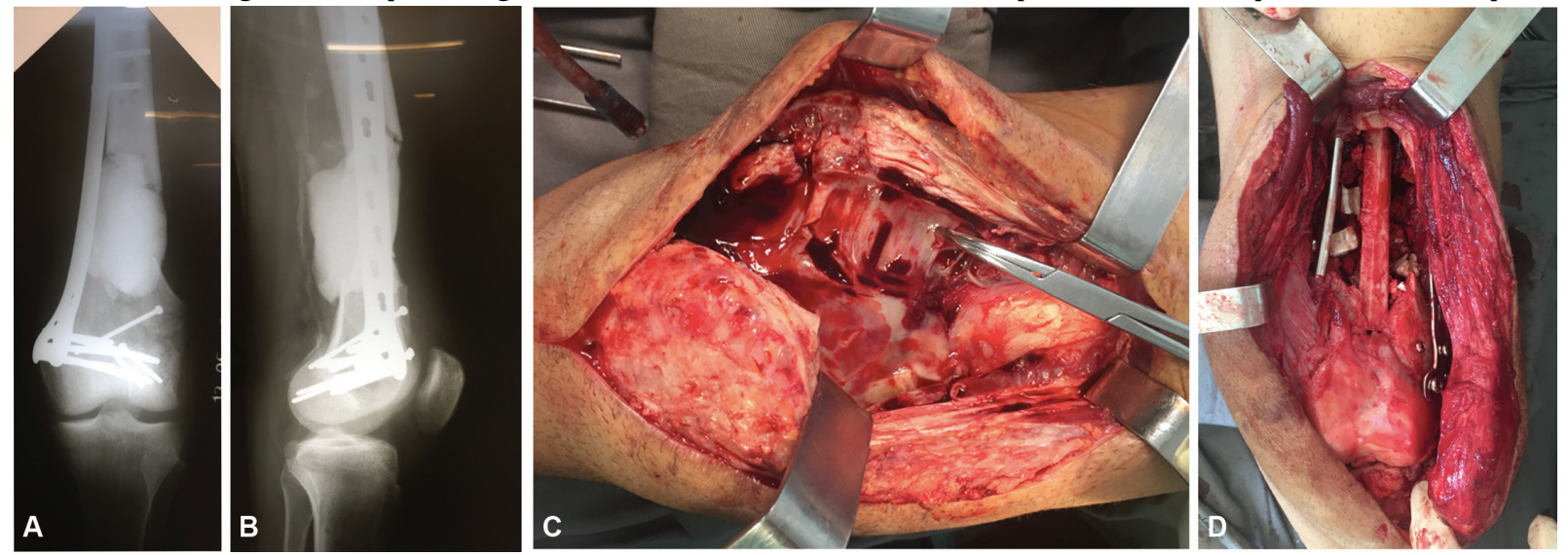

Fig. 2 (A e B) Radiografias em incidências anteroposterior(AP) e de perfil demonstrando falha óssea preenchida com cimento ortopédico e fixação dos fragmentos articulares, e placa bloqueada medial. (C) Membrana vascularizada após a remoção do cimento - ponta da pinça. (D) Falha óssea preenchida com enxerto de fíbula e de crista ilíaca. 

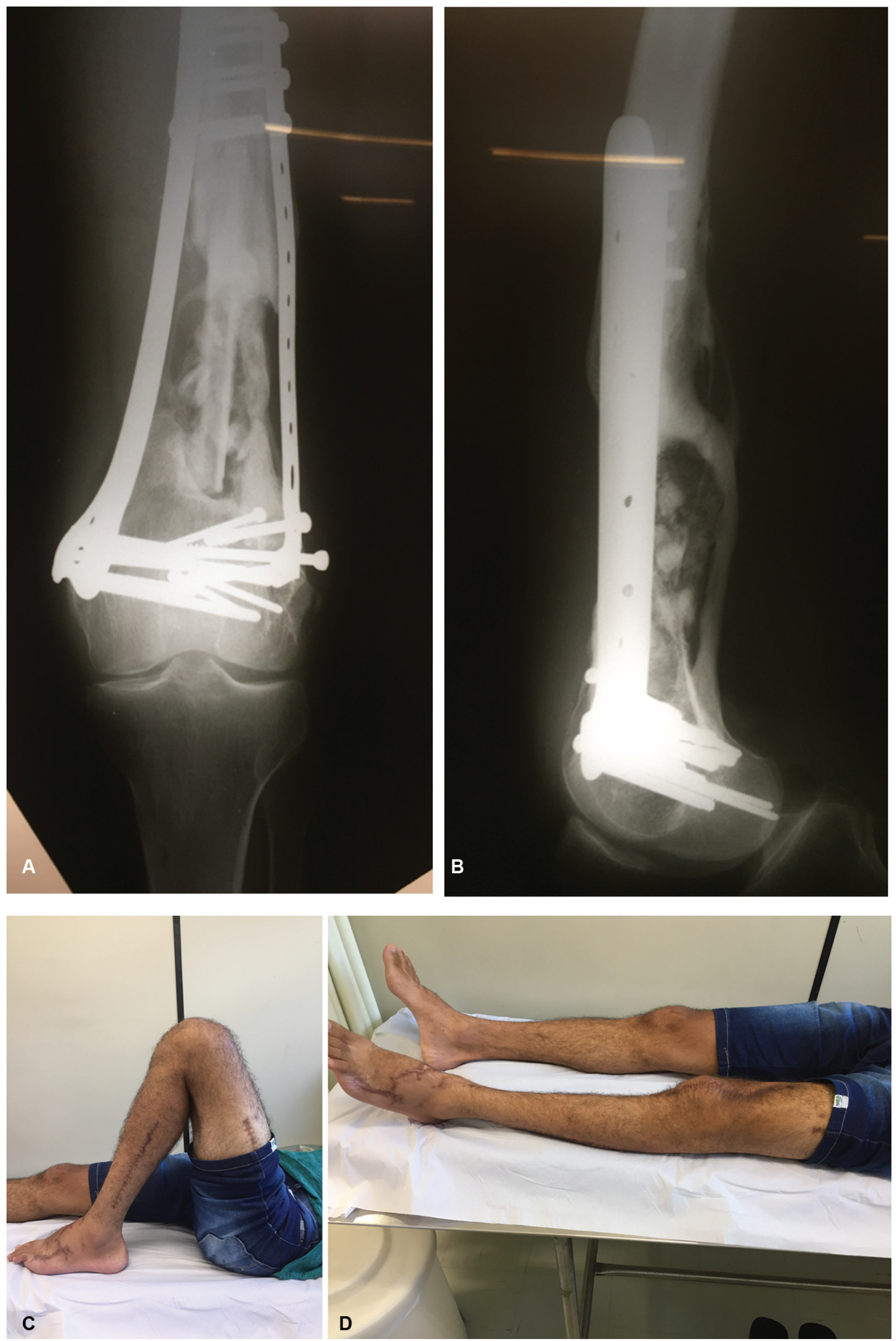

Fig. 3 (A e B) Radiografias em incidências anteroposterior(AP) e de perfil demonstrando consolidação óssea. (C e D) Amplitude de movimento final.

removida. Dois meses após a remoção da placa,o paciente iniciou queixa de dor na região do joelho, e foram feitas novas imagens. Observou-se pseudoartrose distal do fêmur com segmento ósseo inviável ( - Fig. 4A e B). A cicatriz operatória não apresentava sinais de infecção, e o nível de proteína Creativa
(PCR) era de $18 \mathrm{mg} / \mathrm{L}$. No exame físico, o paciente apresentava um encurtamento de $5 \mathrm{~cm}$, e um alinhamento em varo de $6^{\circ}$.

0 paciente foi submetido a ressecção de todo o osso desvitalizado por meiode um acesso anterolateral, fixação com placa bloqueada lateral, e envio de material para cultura. 

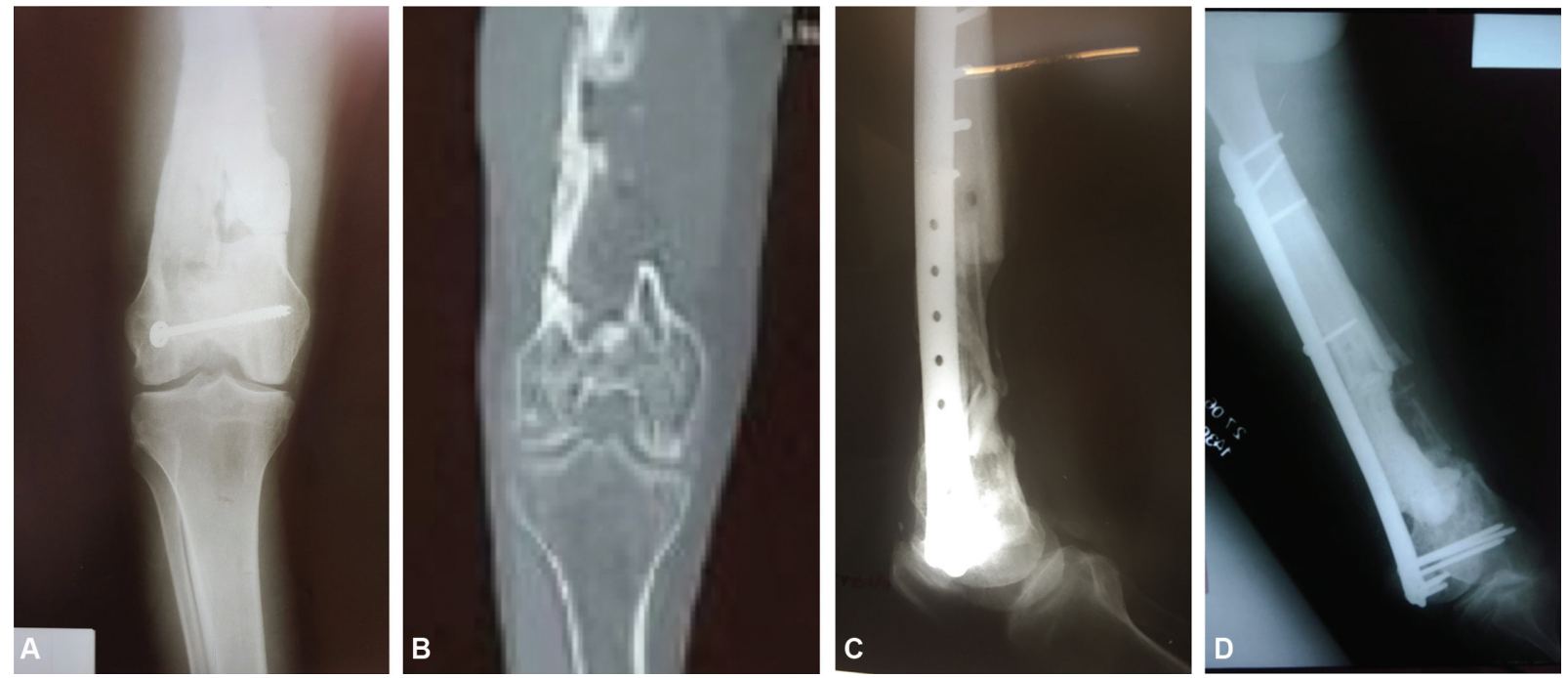

Fig. 4 (A e B) Radiografias em incidência anteroposterior(AP) e tomografia computadorizada (TC) demonstrando segmento ósseo inviável e pseudoartrose da região distal do fêmur. (C e D) Tecido ósseo desvitalizado removido, e defeito preenchido com cimento ortopédico, com antibiótico e fixação com placa bloqueada lateral (raio X, RX).

O defeito ósseo media $11 \mathrm{~cm}$, e foi preenchido com cimento ortopédico e $8 \mathrm{~g}$ de vancomicina; a função renal foi acompanhada a cada 48 horas devido ao risco de toxicidade sistêmica pelo antibiótico ( - Fig. 4C e D). O comprimento final do membro foi obtido por leve tração manual, de acordo com a complacência dos tecidos moles, com preocupação especial para o feixe neurovascular, que foi inspecionado por visão direta na região distal do fêmur durante 0 ato cirúrgico, após a dissecção dos tecidos,mediante uma ampla exposição, de modo que não houvesse tração excessiva em tais estruturas. Na cultura, houve crescimento de Staphylococcusepidermidis e Bacillus sp., que foram tratadas com $2 \mathrm{~g}$ de cefepima de $8 \mathrm{em}$ 8horas, e $600 \mathrm{mg}$ de clindamicina de 6 em 6 horas, por via endovenosa, durante 6 semanas.

Após 6 semanas, o nível de PCR era menor do que $10 \mathrm{mg} / \mathrm{L}$, e procedeu-se ao segundo tempo cirúrgico. $O$ cimento foi removido, e o defeito, preenchido com enxertos de fíbula vascularizada e de crista ilíaca ( - Fig. 5A). No momento da retirada do enxerto da crista ilíaca, foi obtido aspirado de medula óssea da crista, que foi infiltrado no defeito ósseo da região distal do fêmur após o fechamento dos tecidos. Esse aspirado da crista ilíaca foi obtido por punção com agulha de biópsia óssea, e o material não sofreu processamento. Novas culturas, incluindo culturas do osso e de partes moles, foram colhidas após a remoção do espaçador de cimento, totalizando seis amostras, e não houve crescimento bacteriano. 0 paciente recebeu alta hospitalar com tratamento com Amoxicilina + ácido clavulânico oral 500/125 mg de 8em 8horas durante 6 meses, e o controle do processo infeccioso foi realizado por meiodo hemograma, níveis de PCR, e velocidade de hemossedimentação. 0 apoio com carga parcial foi iniciado com 4 meses e, após 1 ano, a fratura se consolidou, a amplitude de movimento do joelho era de $0^{\circ}$ a $120^{\circ}$, a discrepância dos membros era de $2 \mathrm{~cm}$, e o alinhamento do membro, neutro (-Fig. 5B e D).

\section{Discussão}

Este artigo apresenta o tratamento de duas lesões complexas do joelho por meioda técnica de Masquelet, demonstrando que grandes perdas ósseas podem ser manejadas sem o uso de dispositivos de transporte ósseo.
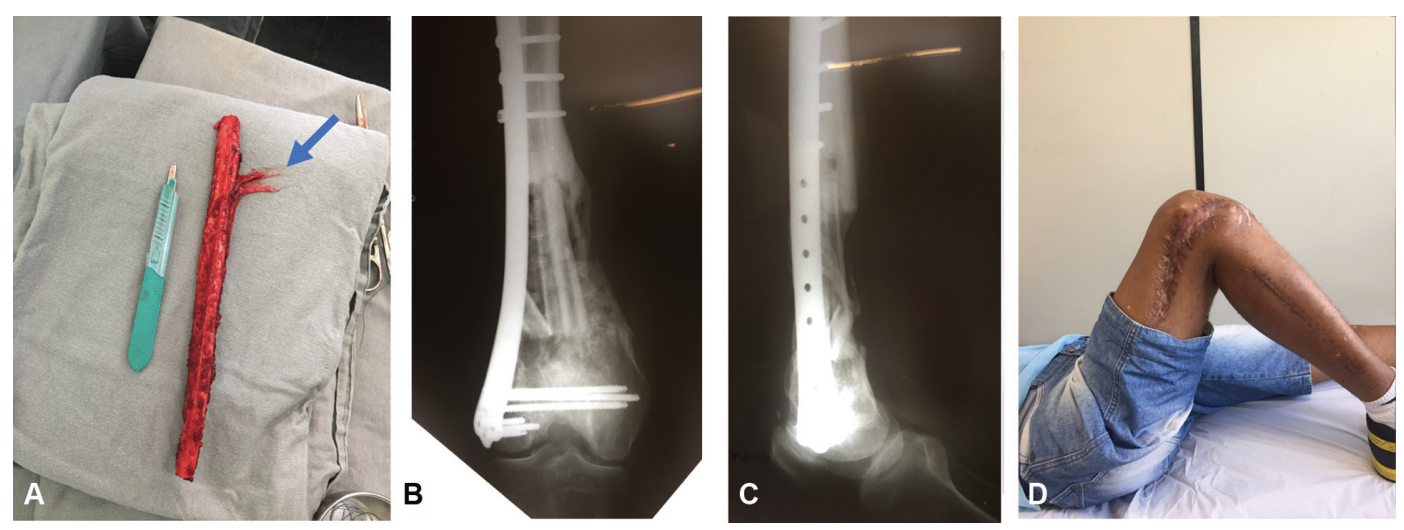

Fig. 5 (A) Enxerto autólogo de fíbula vascularizada (seta - vaso sanguíneo). (B e C) Radiografia pós-operatória demonstrando a consolidação. (D) Amplitude de movimento. 
A técnica de Masquelet envolve a formação de uma membrana vascularizada e o preenchimento do defeito com enxerto ósseo autólogo. A técnica envolve o uso de um espaçador de cimento de polimetilmetacrilato, que leva à formação da membrana que previne a reabsorção do enxerto ósseo e cria um ambiente ideal para a consolidação. ${ }^{7-10}$ Apesar de a descrição da técnica de Masquelet envolver o tratamento de falhas ósseas de até $25 \mathrm{~cm}$, a literatura apresenta estudos nos quais as falhas geralmente não ultrapassam $7 \mathrm{~cm}$, devido à fonte limitada de enxerto ósseo autólogo de crista ilíaca. ${ }^{11}$

Dugan et al $^{12}$ obtiveram consolidação óssea em 15 fraturas expostas da região distal do fêmur tratadas agudamente pela técnica em dois estágios, como a apresentada no primeiro relato de caso. 0 tamanho da falha óssea variou entre 2 e $11 \mathrm{~cm}$, e foi preenchida com enxerto de crista ilíaca e suplementação com aloenxerto nos defeitos maiores. Nos casos apresentados anteriormente,optamos pelo uso de enxerto de fíbula e suplementação com enxerto de crista ilíaca, afim de preencher o defeito ósseo e darmaior estabilidade à fratura com o uso da fíbula. Além disso, demonstramos que grandes defeitos ósseos podem ser manejados com sucesso sem o uso de aloenxertos. ${ }^{12}$

Donegan et al $^{13}$ utilizaram técnica semelhante à apresentada, envolvendo uso de espaçadores com antibiótico e posterior enxertia óssea. O estudo envolveu fraturas agudas com perda óssea e pesudoartroses infectadas e não infectadas de fêmur e tíbia,e aconsolidação da fratura foi alcançada em 10 dos 11 casos tratados. $^{13}$

O presente estudo apresenta 2 casos de falhas ósseas de 9 e $11 \mathrm{~cm}$ em que a capacidade limitada de enxerto autólogo de crista ilíaca foi superada por meioda associação de enxerto de fíbula, não sendo necessária a utilização de aloenxerto. ${ }^{14}$ No primeiro caso apresentado, utilizou-se a fíbula não vascularizada, e, no segundo caso, utilizou-se fíbula vascularizada devido ao maior defeito ósseo. A retirada de enxerto da fíbula em ambos os casos foi realizada pela equipe de microcirurgia. Isso pode representar uma limitação para o uso da técnica em serviços ortopédicos sem equipe com treinamento em microcirurgia no caso de obtenção da fíbula vascularizada. Consideramos que o enxerto de fíbula não vascularizada pode ser obtido por ortopedista sem treinamento microvascular, masoptamos pela abordagem conjunta com a equipe de microcirurgia. Allsopp et al, ${ }^{15}$ em uma revisão sistemática, demonstraram que não há evidência de que defeitos ósseos maiores do que 6 centímetros devem ser tratados com enxertos vascularizados, e que não houve diferença no tempo e nas taxas de consolidação comparando enxertos vascularizados e não vascularizados. Isso permite que enxertos sejam obtidos em serviços de Ortopedia sem equipe de cirurgia microvascular.
A técnica de Masquelet associada a enxerto de crista ilíaca e fíbula vascularizada demonstrou bom resultado funcional e consolidação óssea nos dois casos apresentados pelos autores.

Conflito de Interesses

Os autores declaram não haver conflito de interesses.

\section{Referências}

1 DeCoster TA, Gehlert RJ, Mikola EA, Pirela-Cruz MA, DeCoster TA. Management of posttraumatic segmental bone defects. J Am Acad Orthop Surg 2004;12(01):28-38

2 Rezzouk J, Leclerc J, Leger O, Boireau P, Fabre T, Durandeau A. Bone reconstruction with induced membranes and cancellous autograft: results in 18 cases of osteitis. J Bone Joint Surg Br 2005;87 (Suppl 2):98

3 Masquelet AC, Begue T. The concept of induced membrane for reconstruction of long bone defects. Orthop Clin North Am 2010; 41(01):27-37

4 Chong KW, Woon CY, Wong MK. Induced membranes-a staged technique of bone-grafting for segmental bone loss: surgical technique. J Bone Joint Surg Am 2011;93(Suppl 1):85-91

5 Ahmad S, Kalra M, Selvamari M. Induced membrane formation in a case of infected gap nonunion of radius: Case report. J Clin Orthop Trauma 2013;4(03):147-150

6 Gustilo RB, Mendoza RM, Williams DN. Problems in the management of type III (severe) open fractures: a new classification of type III open fractures. J Trauma 1984;24:742-746

7 Giannoudis PV. Treatment of bone defects: Bone transport or the induced membrane technique? Injury 2016;47(02):291-292

8 Pelissier P, Martin D, Baudet J, Lepreux S, Masquelet AC. Behaviour of cancellous bone graft placed in induced membranes. Br J Plast Surg 2002;55(07):596-598

9 Pelissier P, Masquelet AC, Bareille R, Pelissier SM, Amedee J. Induced membranes secrete growth factors including vascular and osteoinductive factors and could stimulate bone regeneration. J Orthop Res 2004;22(01):73-79

10 Pelletier MH, Malisano L, Smitham PJ, Okamoto K, Walsh WR. The compressive properties of bone cements containing large doses of antibiotics. J Arthroplasty 2009;24(03):454-460

11 Chmell MJ, McAndrew MP, Thomas R, Schwartz HS. Structural allografts for reconstruction of lower extremity open fractures with 10 centimeters or more of acute segmental defects. J Orthop Trauma 1995;9(03):222-226

12 Dugan TR, Hubert MG, Siska PA, Pape HC, Tarkin IS. Open supracondylar femur fractures with bone loss in the polytraumatized patient - Timing is everything!. Injury 2013;44(12): 1826-1831

13 Donegan DJ, Scolaro J, Matuszewski PE, Mehta S. Staged bone grafting following placement of an antibiotic spacer block for the management of segmental long bone defects. Orthopedics 2011; 34(11):e730-e735

14 Levin LS. Vascularized fibula graft for the traumatically induced long-bone defect. J Am AcadOrthop Surg 2006;14(10 Spec No.): S175-S176

15 Allsopp BJ, Hunter-Smith DJ, Rozen WM. Vascularized versus Nonvascularized Bone Grafts: What Is the Evidence? Clin Orthop Relat Res 2016;474(05):1319-1327 